REVISTA

MEXICANA DE

ECONOMÍA Y

FINANZAS

REMEF

(TIIE MEXICAN JOURNAL OF

ECONOMICS AND FINANCE
Revista Mexicana de Economía y Finanzas, Nueva Época

Volumen 17 Número 2, Abril - Junio 2022, pp. 1-23, e659

DOI: https://doi.org/10.21919/remef.v17i2.659

(Recibido: 24/mayo/2021, aceptado: 2/septiembre/2021, publicado: 4/noviembre/2021)

\title{
Factores asociados a la adopción de la banca electrónica en México
}

\author{
José Wilmar Quintero Peña1 - Institución Universitaria Politécnico Grancolombiano, Colombia \\ Manuel Antonio Mejía Baños² - Fundación Universitaria Los Libertadores, Colombia
}

El presente artículo tiene como objetivo identificar los factores asociados a la adopción de la banca electrónica en México, utilizando la Encuesta de Tecnologías de la Información y Comunicación del INEGI 2019; para lo cual, se utilizó el modelo probabilístico Logit y el modelo supervisado de árboles de decisión. Los resultados de esta investigación pretenden dar insumos para formular políticas públicas y estrategias de inclusión financiera. Entre las limitantes se encuentran los datos perdidos de variables de gran importancia, así como la no disponibilidad de características más específicas de la población. La aportación original es el uso de herramientas de aprendizaje profundo en el análisis de la adopción de banca electrónica para una economía en desarrollo. Se concluyó que: los individuos con mayor nivel educativo, usuarios frecuentes de Internet, de estratos socioeconómicos altos y habitantes de los centros urbanos más poblados, son quienes adoptan fácilmente la banca electrónica. Clasificación JEL: E58, G28, 016, O33, P34.

Palabras clave: arboles de decisión, banca electrónica, Logit, inclusión financiera.

\section{Factors Associated to Electronic Banking Adoption in Mexico}

This document aims to identify the factors associated with the adoption of electronic banking in Mexico, using the Information and Communication Technologies Survey from INEGI 2019; for which, a probabilistic Logit model and the supervised model of decision tree were used. Results from this research intend to provide inputs to develop public policy and financial inclusion strategies. Its limits include lost data from significant variables, as well as the non-availability of more specific characteristics of population. The original contribution is the in-depth use of learning tools in the adaption of electronic banking analysis for a developing economy. It was concluded that individuals with higher education level, frequent Internet users, from high socioeconomic strata and inhabitants of the most populated urban centers are who adopt electronic banking easily.

JEL Classification: E58, G28, 016, 033, P34.

Keywords: random forests, electronic banking, Logit, financial inclusion.

\footnotetext{
${ }_{1}^{1}$ Autor de correspondencia. Docente-Investigador, Politécnico Grancolombiano. E-mail:jquinterop@poligran.edu.co 2 Magister en In Scienze Politiche Per La Pace El Integrazione Dei Popoli, Università Degli Studi di Salerno di Italia. Docenteinvestigador, Fundación Universitaria los Libertadores - Colombia. E-mail: mamejiab@libertadores.edu.co.

*Sin fuente de financiamiento para el desarrollo de la investigación
} 


\section{Introducción}

El uso de los medios electrónicos en la cotidianidad laboral, social y personal se ha convertido en una necesidad latente. Por otra parte, con la aparición del COVID-19 - que ha obligado a los países y al mundo a entrar en confinamiento general con el objetivo de preservar la vida y contener el nivel de contagio-, se ha hecho evidente la importancia de los medios electrónicos y tecnológicos en el quehacer diario de la sociedad.

En México, donde el virus ha golpeado con gran fuerza de contagio y letalidad (Secretaría de Salud México,2021), pensar en el uso de los medios electrónicos para realizar operaciones financieras - acceder a los bancos, realizar pagos, acceder a crédito y demás - es una alternativa importante para que la población no se exponga al virus. Por ello, el objetivo del presente artículo es analizar los factores que determinan la adopción de la banca electrónica por parte de la población mexicana.

A raíz de la expansión del COVID-19, se han replanteado muchas actividades humanas, entre ellas la forma de trabajar y relacionarnos con los demás. Todo esto con el fin de evitar los contagios por aglomeraciones. En este sentido, la adopción de la banca electrónica es una alternativa para evitar la asistencia física a una sucursal bancaria y exponerse a espacios con gran afluencia.

Desde esta perspectiva, es preciso decir que el uso de los medios electrónicos en las labores cotidianas, tanto para las familias como para los sectores productivos, llegó para quedarse. Por tal motivo, la adopción de la banca electrónica debe ser una realidad que le permita a las personas el acceso rápido y seguro a las diferentes operaciones bancarias. Además, debe ser una forma apta para democratizar la inclusión financiera de la población y permitir acceso a nuevos mercados en diferentes latitudes. Lo cual es posible y necesario, teniendo en cuenta que la banca electrónica hace parte y es eje fundamental del desarrollo del comercio electrónico. Sin embargo, los matices de la adopción de la banca electrónica por parte de los habitantes de una nación dependen de muchos factores políticos, culturales y tecnológicos, entre otros.

No obstante, el presente estudio analiza el acceso a la banca electrónica en México, lo que permite entender el funcionamiento del uso de las distintas tecnologías digitales que ofrece el mercado. Dado los grandes avances en la digitalización promovidos por la banca tradicional y principalmente por las Fintech (Tecnologías Financieras por su sigla en inglés Finance Technology), es relevante analizar los determinantes socioeconómicos que se relacionan con la adopción de la banca electrónica. Ese conocimiento no solo es importante para la promoción de políticas de inclusión financiera, sino también para los desarrolladores de nuevos modelos de negocios intensivos en el uso de datos.

Aquí se amplía la poca literatura que estudia los determinantes de la adopción de la banca electrónica en países en desarrollo. Además, a diferencia de la mayoría de las investigaciones, la presente no se limita a usar los modelos de regresión clásicos, sino que también incluye los árboles de decisión, metodología del aprendizaje de la máquina que permite generar una secuencia de cómo los consumidores ordenan sus decisiones. Así se convierte en un trabajo pionero el estudio de adopción de tecnologías digitales en contextos de países en desarrollo.

Como señala Suárez (2016), tras realizar un análisis diferencial de la adopción de dinero móvil en México y Kenia, la baja adopción de este tipo de pago en México obedece a la "captura del 
regulador", refiriéndose a las fuertes regulaciones presentes en el país. Por el contrario, en las últimas décadas, Kenia presenció un enorme crecimiento del uso del dinero móvil que involucró la inclusión financiera de su población. Fenómeno explicado por los bajos niveles regulatorios del país africano.

En esta orden de ideas, Ángel (2016) señala que en México existen tres clases de personas, agrupadas según las condiciones que causan la baja adopción de pagos electrónicos: el primer grupo se caracteriza por tener una baja inclusión financiera; el segundo corresponde a quienes no conciben que los pagos digitales funcionen como dinero, y el tercero está compuesto por quienes requieren mejoras en la implementación y en la confiabilidad de las transacciones de pago.

Esto se traduce en importantes retos, como se aprecia en la figura 1, más del 32\% de las personas encuestadas manifestaron que prefieren realizar pagos de forma presencial, antes que operaciones electrónicas.

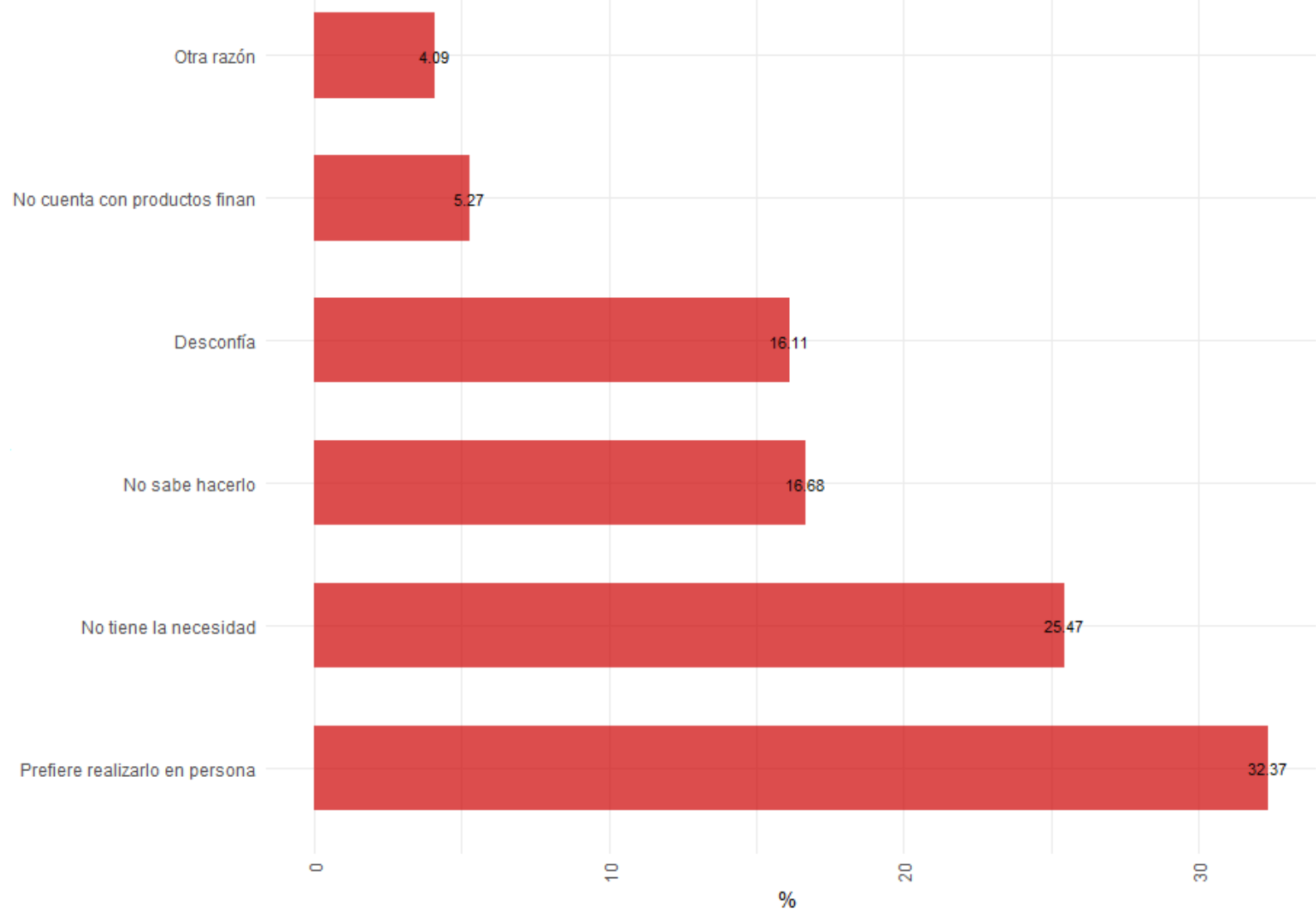

Figura 1. Razones por la que las personas en México no realizan pagos en línea. Nota: Elaboración propia con base a ENDUTIH-2019.

Como se evidencia en la figura 1, algunas de las principales razones que actualmente limitan la realización de pagos digitales por parte de los ciudadanos son: creer que no tienen necesidad de hacerlo; no saber hacerlo, y desconfiar del uso de herramientas tecnológicas para este tipo de operaciones.

En esa misma línea, Ángel (2016) señala que otro importante factor de la baja adopción de pagos electrónicos es la existencia de la economía informal. La práctica de usar dinero en efectivo, por parte de este amplio sector de la economía, evita la vigilancia y reporte electrónico a las 
autoridades. Máxime cuando en este mundo se solapan las actividades criminales y de comercio ilegal.

De otra parte, la población que utiliza la banca electrónica en México realiza mayormente operaciones de: consulta de saldo, transferencias, pagos de servicios públicos y compra de minutos para celular o tiempo al aire, como se observa en la figura 2. Como afirma el Instituto Nacional de Estadística y Geografía (INEGI) la banca electrónica se define así: “Conjunto de productos y procesos que permiten, mediante procedimientos informáticos, que el cliente pueda realizar transacciones bancarias sin necesidad de ir a la sucursal".

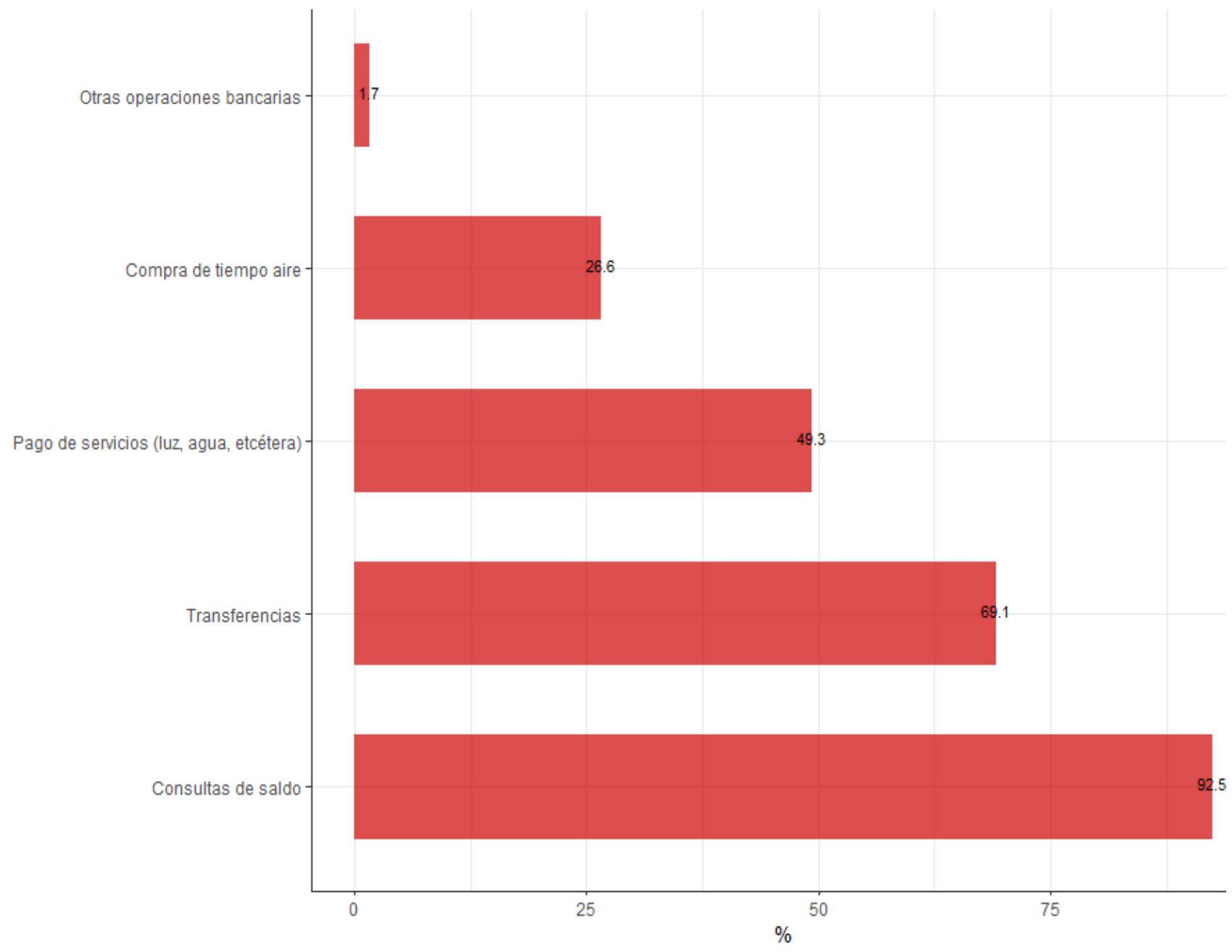

Figura 2. Operaciones realizadas por medio de Banca electrónica Nota: Elaboración propia con base a ENDUTIH-2019.

No obstante, el uso del Internet y la tecnología en las actividades cotidianas se han convertido en una necesidad cada vez más apremiante. En el sector financiero, el uso de la tecnología ha mejorado las operaciones bancarias, tanto para los usuarios como para los bancos. Para autores como Mobayen, Ghahremani, Hasanpoor \& Joorbonyan (2015) y Wanjiku \& Mbugua (2018), la implantación de la banca electrónica genera mayores ganancias y competitividad operativa en las 
entidades que la implementan. Según Muwando \& Webb (2014), la banca electrónica mejoró la eficiencia operativa de los bancos que la implementaron en Zimbabwe. Desde la posición de Ikhsanova \& Protski (2016), el uso de la banca electrónica mejoró la calidad de los servicios bancarios en Rusia. Para Mohammadi (2008) y Ali, Khalid \& Omer (2020), la banca electrónica permite acceso fácil a los servicios bancarios y financieros por parte de los usuarios.

Teniendo presente todo lo anterior, este artículo se estructura en cuatro partes: en la primera, se presenta el estado del arte sobre la adopción de la banca electrónica a nivel mundial; en la segunda, se presentan la metodología y las especificaciones del modelo econométrico, así como las estadísticas descriptivas sobre usuarios y no usuarios de la banca electrónica en México; en la tercera, los resultados de las estimaciones del modelo Logit (efectos marginales, coeficientes lineales, heterogeneidad por tamaño de la población), y del Árbol de decisión sobre la adopción de la banca electrónica; por último, en la cuarta parte, se presentan las conclusiones y discusiones finales.

\section{Revisión de literatura}

Vejačka \& Stofa (2017) estudiaron a través de un Modelo de Aceptación de Tecnología (Technology Acceptance Modelling, TAM) los determinantes de la adopción de banca electrónica en Eslovaquia y concluyeron que la seguridad y la percepción de confianza del usuario son los determinantes más importantes para adoptar la banca electrónica en dicho país. En un estudio anterior, también realizado mediante un modelo TAM, Vejačka (2014) determinó que las mujeres, la población entre los 20 a los 29 años y quienes consideran tener información suficiente sobre banca electrónica y perciben su utilidad, tienen mayor probabilidad de usar banca electrónica en Eslovaquia.

En Ucrania, el uso de la banca electrónica está limitado por la falta de seguridad y de legislación que protejan al consumidor (Kapinus \& Skrygun, 2014). Sucede algo similar en la India, donde los problemas legales, socioculturales y de seguridad dificultan el uso de la banca electrónica (Karimzadeh \& Alam, 2012). Para Inegbedion (2018), el conocimiento que tiene el usuario sobre el Internet y la facilidad de uso que perciba influyen positivamente en el uso de la banca electrónica. En Nigeria, la desconfianza en navegar en la red de los usuarios de Internet influye de manera negativa en su uso. En esta misma línea, Jerene \& Sharma (2020), a través de un modelo TAM, determinaron que el riesgo financiero percibido por los usuarios influye de manera negativa en la decisión de usar la banca electrónica en Etiopia.

Desde la posición de Yates (2020), el conocimiento financiero, los ingresos, la educación y la posesión de tarjetas de crédito están asociados con una alta probabilidad de adopción de la banca electrónica. Por su parte, la edad avanzada se asocia negativamente con la probabilidad de adopción de la banca en línea y es menos probable que el consumidor afroamericano adopte la banca electrónica en EE.UU. Los autores Lee \& Lee (2000), utilizando la encuesta del consumidor financiero de 1995 y basándose en la teoría de innovación y difusión, realizaron un análisis multivariado a través de un modelo Logit y determinaron que en EE.UU los consumidores más educados, más ricos y más jóvenes tienden a adoptar la banca electrónica más fácilmente que otros grupos poblacionales.

En Sudáfrica, los excluidos financieros no están dispuesto a usar la banca electrónica, pero entre las personas de altos ingresos su uso tiene alta aceptación (Bimha, 2015). Por otra parte, para Borraz, Bordonaba \& Polo (2017), la percepción de complejidad y riesgo en el uso de la banca electrónica limitan las posibilidades de su adopción. 
En México la literatura sobre factores determinantes en la adopción de banca electrónica es escasa, sin embargo, existen importantes investigaciones tendientes a explicar y caracterizar los retos de la banca digital. Avendaño (2017) establece que los principales retos de la banca digital en México se centran en encontrar un mecanismo de verificación de claves y usuarios de accesos que brinde confianza a los consumidores.

También (Araiza \& Pedraza, 2019) plantean que en el área metropolitana de Monterrey, México, la utilidad y la facilidad de uso percibida por los usuarios tiene una incidencia significativa en la adopción de los servicios financieros en línea. Por su parte Ramírez, García, \& Aranibar (2019) establecen que la satisfacción y la confianza son variables relacionadas de manera positiva con el uso de la banca en línea en México.

Así pues, Mejía \& Quintero (2016) analizaron los determinantes del uso de la banca electrónica en Colombia, a través de un modelo probabilístico tipo Logit. Determinaron que existen marcadas diferencias regionales en la adopción de la banca electrónica. Asimismo, concluyeron que las personas que usan Internet con alta frecuencia, los jefes de hogar, quienes tienen entre 34 y 45 años, los hombres, las personas con ingresos altos y las personas con estudios universitarios tienen una mayor probabilidad de usar la banca electrónica en Colombia.

En esta misma línea, Flavián, Guinaliu \& Torres (2006) plantean que la edad, el sexo y los ingresos son factores que influyen en la adopción de la banca electrónica. Para el uso frecuente del Internet, la tenencia de otro producto financiero y la confianza en la entidad financiera, influyen positivamente en el uso de la banca electrónica (Meyer, 2006; Lassala, Ruiz \& Blas, 2007; y Szopiński ,2016). Citando a Angelakopoulos \& Mihiotis (2011) encuentran que la educación es un factor determinante en el uso de la banca electrónica.

Por otra parte, Valverde \& Fernández (2019) hacen un llamado a realizar investigaciones sobre la adopción de servicios financieros digitales, que incluyan el aprendizaje requerido para utilizar la máquina y los procesos neurológicos involucrados. En la discusión que plantean los autores, se señala que estos aspectos son muy importantes para entender en mayor detalle cómo toman decisiones los usuarios de servicios digitales. Tras analizar el caso de España, que estudian usando estos dos aspectos, sus resultados señalan que, una vez adoptadas la consulta de saldos financieros en línea, la consciencia sobre sus productos financieros y el pago de facturas por Internet, el usuario va digitalizándose progresivamente. Resultados que no solo aportan para responder preguntas sobre los determinantes, sino que pueden ayudar a entender mejor el funcionamiento de la decisión de adoptar o no la banca electrónica.

Otra línea que viene tomando fuerza en la explicación del uso de la banca electrónica es el surgimiento de la Fintech. En México, esta es una alternativa importante en el mundo de las finanzas, debido a que las empresas Fintech conquistan el mercado financiero con servicios ágiles, fáciles y de bajo costo, a través de páginas web que mejoran la accesibilidad de muchos usuarios a dichos servicios. El incremento de la oferta de productos financieros a través empresas Fintech en el segmento de pagos, es evidencia de ello en México, donde las remesas y prestamos han incrementado en $20.2 \%$ y 23.1\% respetivamente, según el Banco Interamericano de Desarrollo (2018). En 2019, esta versatilidad de las Fintech llevó a que el Índice Global de Adopción de Fintech fuera del 72\% (Global FinTech Adoption Index, 2019). 
En coherencia con lo anterior, se observa que México es el país latinoamericano que presenta un mayor grado de desarrollo regulatorio con respecto a la Ley de la Fintech (Lavalleja, 2020). Dicha ley está basada en los principios de "inclusión e innovación financiera, promoción de la competencia, protección al consumidor, preservación de la estabilidad financiera, prevención de operaciones ilícitas y neutralidad tecnológica".

Según el Fondo Monetario Internacional (2019), la importancia del avance en la regulación y de la adopción de la Fintech, es que, debido a la operatividad de tales emprendimientos, las empresas Fintech tienen el potencial de impulsar la competencia y poner presión sobre los márgenes, aliviando así las consecuencias adversas de una alta concentración del sistema bancario tradicional. Lo cual podrá traducirse en una mayor inclusión financiera en el territorio mexicano.

\section{Métodología}

\subsection{Especificaciones y modelos}

Para analizar los determinantes del uso de banca electrónica en México se propone un análisis de regresión múltiple, con variable dependiente binaria que está representada por 1 , si la persona encuestada reportó usar banca electrónica, y por 0 , en caso contrario. Puntualmente se establece la siguiente especificación:

$$
\begin{aligned}
Y_{i}=\beta_{0} & +\beta_{1} \text { Th }+\beta_{2} \text { Rural }+\beta_{3} \text { Estrato }+\beta_{4} \text { Sexo }+\beta_{5} \text { Edad }+\beta_{6} \text { Educación }+\beta_{7} \text { Empleado } \\
& +\beta_{8} \text { Usuario freq internet }+\beta_{9} \text { Jefe }+\beta_{9} \text { Privacidad }+\beta_{9} \text { Fraudes }+ \text { ei }
\end{aligned}
$$

Donde $Y_{i}$ representa la variable dependiente binaria antes mencionada. Dada la estructura binaria de estas variables, se propone el modelo de probabilidad lineal. Así, la regresión corresponde a la probabilidad de que la variable dependiente sea 1 , dadas las diferentes covariables.

Según Stock \& Watson (2019), los coeficientes estimados de cualquier regresor son el cambio en la probabilidad de $Y_{i}=1$ asociado con una unidad de cambio en las covariables. Sin embargo, como también lo señalan Stock \& Watson (2019), logit y probit son modelos de regresión no lineal, específicamente diseñados para variables dependientes binarias. Lo anterior se debe a que, para una regresión con una variable dependiente binaria, tiene más sentido adoptar una formulación no lineal que acote los valores predichos antes que acotarlos entre cero y uno. Otro argumento a favor es el relacionado con el hecho de que la distribución de probabilidad acumulada produce probabilidades entre cero y uno.

Se utiliza el modelo Logit — que tiene una función de distribución acumulada de probabilidad, porque supone una distribución logística en los residuales del modelo con variable latente. La siguiente ecuación presenta la función de distribución logística no lineal:

$$
\mathrm{P}\left(\mathrm{Y}_{i}=1 /\left(X_{1}, X_{2}, \ldots, X_{k}\right)=F\left(\beta_{0}+\beta_{1} X+\beta_{2} X+\cdots+\beta_{\mathrm{K}} X_{k}\right)=\frac{1}{1+e^{-\left(\beta_{0}+\beta_{1} X+\beta_{2} X+\cdots+\beta_{\mathrm{K}} X\right)}}\right.
$$

Las estimaciones se realizan por el método de máxima verosimilitud. Lo que presenta dificultades para su interpretación respecto al Método de Mínimos Cuadrados Ordinarios (MCO). Por 
tanto, es más conveniente usar los efectos marginales, o sea, la derivada parcial de la probabilidad respecto a cada una de las variables en su valor promedio, que se definen de la siguiente manera:

$$
\frac{\partial \mathrm{P}\left(\mathrm{Y}_{i}=1 / X\right)}{\partial X_{k}}=\frac{\partial \mathrm{E}(\mathrm{Y} / X)}{\partial X_{k}}=\frac{\partial \mathrm{F}(\mathrm{X} \beta)}{\partial X_{k}}=f(\mathrm{X} \beta) \beta_{i}
$$

Establecen Álvarez et al. (2013) que su interpretación se funda en el efecto que tiene un cambio en una unidad de $X_{k}$ sobre la probabilidad de que se presente el evento determinado, manteniendo constante las demás variables explicativas.

Atendiendo el llamado de Valverde \& Fernández (2019) sobre la importancia de estudiar la adopción de servicios financieros digitales no de forma econométrica sino incluyendo herramientas del Aprendizaje Automático y la Neuroeconomía, se realizó un ejercicio complementario. Es así como, en el presente estudio se incluyó en particular el Aprendizaje Automático, mediante la metodología de "bosques de decisión" que analiza la secuencia en la ocurrencia de variables que determinan que los usuarios de banca electrónica tomen la decisión de adoptarla.

\subsection{Fuente de la Data}

Los datos analizados provienen de la Encuesta Nacional sobre Disponibilidad y Uso de Tecnologías de la Información en los Hogares (ENDUTIH) 2019. Se utilizaron los cuatro módulos de información, especialmente el referente a usuarios de TIC que contiene 21.620 observaciones. Después de realizar la limpieza de la base de datos con las variables utilizadas, las observaciones válidas se reducen a cerca de 13.000. A continuación, en la tabla 1, se describen las variables utilizadas en el modelo a estimar.

Tabla 1. Variables implementadas en las estimaciones

\begin{tabular}{|c|c|}
\hline Variables & Detalle de la variable según la ENDUTIH \\
\hline Banca electrónica (1=usa; $0=$ no usa ) & En los últimos tres meses, ¿ha hecho uso de la banca electrónica? \\
\hline Tamaño del hogar (Th) & $\begin{array}{l}\text { Total de personas en la vivienda }<=4 \text { personas toma el valor de } \\
\text { uno; } 0 \text {, si es mayor. }\end{array}$ \\
\hline Tamaño de la población & $\begin{array}{l}1=100.000 \text { o más habitantes } \\
2=15.000 \text { a } 99.999 \text { habitantes } \\
3=2.500 \text { a } 14.999 \text { habitantes } \\
4=\text { menor de } 2.500 \text { habitantes }\end{array}$ \\
\hline Área (Rural=1; Urbana=0) & Población rural y urbana \\
\hline Estrato socioeconómico ${ }^{3}$. Bajo(referencia) & $\begin{array}{l}1 \text { Bajo } \\
2 \text { Medio bajo } \\
3 \text { Medio alto } \\
4 \text { Alto }\end{array}$ \\
\hline Sexo (1=Mujer; 0=Hombre) & $\begin{array}{l}1 \text { Hombre } \\
2 \text { Mujer }\end{array}$ \\
\hline $\begin{array}{l}\text { Edad, }<28(\text { referencia })(1) ;>28-34(2) ;>34-44(3) \\
>45(4) .\end{array}$ & ¿Cuántos años cumplidos tiene (NOMBRE)? \\
\hline
\end{tabular}




\begin{tabular}{|l|l|}
\hline $\begin{array}{l}\text { Educación (1, si es licenciatura o mayor; 0, para grados } \\
\text { menores) }\end{array}$ & $\begin{array}{l}\text { ¿Hasta qué año o grado aprobó (NOMBRE) en la escuela? } \\
\text { Nivel }\end{array}$ \\
\hline $\begin{array}{l}\text { Trabajar (1, si la semana pasada trabajó; 0, caso } \\
\text { contrario). }\end{array}$ & ¿La semana pasada trabajo? \\
\hline $\begin{array}{l}\text { Alta frecuencia en el uso de TIC-dispositivos (1, si es } \\
\text { todos los días, es decir, } 7 \text { días por semana; 0, otra } \\
\text { frecuencia). }\end{array}$ & $\begin{array}{l}\text { Generalmente, ¿cuántos días a la semana usa la computadora, } \\
\text { laptop o tablet? }\end{array}$ \\
\hline $\begin{array}{l}\text { Alta frecuencia uso de Internet, navegar más de seis } \\
\text { horas al día en la red. }\end{array}$ & En promedio, ¿cuántas horas al día utiliza Internet? \\
\hline $\begin{array}{l}\text { Desconfianza (1, si ha sido victima de fraude y violación } \\
\text { de la privacidad; 0, otra situación) }\end{array}$ & $\begin{array}{l}\text { "En los últimos tres meses por el uso del Internet, ¿ha tenido... } \\
\text { fraudes con información (financiera, personal, etcétera)?" y } \\
\text { "7.16 En los últimos tres meses por el uso del Internet, ¿ha } \\
\text { tenido... } \\
\text { violación a la privacidad?" }\end{array}$ \\
\hline $\begin{array}{l}\text { Jefe de hogar(1, si es jefe de hogar; 0, caso contrario) } \\
\text { ¿Qué es (NOMBRE) del jefe(a) del hogar? } \\
1 \text { Jefe(a)(referencia), 2 Esposo(a) o compañero(a), } 3 \text { Hijo(a) } \\
4 \text { Nieto(a), 5 Otro parentesco, 6 Sin parentesco }\end{array}$ \\
\hline
\end{tabular}

Nota: Las variables utilizadas son ad-hoc con base a las empleadas en la literatura y disponibilidad en la ENDUTIH en el año 2019.

\subsection{Estadísticas Descriptivas}

En la tabla 2, se muestran la media y la desviación estándar de las variables empleadas. Allí se aprecia que solo el $16.8 \%$ de los encuestados usan banca electrónica y el $20 \%$ usa Internet más de seis horas. De la misma manera, se aprecian diferencias importantes en las características poblaciones entre los usuarios y no usuarios de banca electrónica.

Tabla 2. Estadística descriptiva

\begin{tabular}{|l|c|c|c|}
\hline Estadístico & $\mathbf{N}$ & Media & St. Dev. \\
\hline Tamaño del hogar & 13,193 & 0.715 & 0.452 \\
\hline Rural & 13,193 & 0.254 & 0.435 \\
\hline Tamaño de la población & 13,193 & 2.116 & 1.282 \\
\hline Estrato & 13,193 & 2.422 & 1.042 \\
\hline Edad & 13,193 & 2.434 & 1.260 \\
\hline Banca electrónica & 13,193 & 0.168 & 0.374 \\
\hline Jefe & 13,193 & 0.396 & 0.489 \\
\hline Sexo & 13,193 & 0.474 & 0.499 \\
\hline Educación & 13,193 & 0.283 & 0.451 \\
\hline Alta freq internet & 13,193 & 0.202 & 0.401 \\
\hline Fraudes & 13,193 & 0.045 & 0.208 \\
\hline Ocupados & 13,193 & 0.593 & 0.491 \\
\hline Privacidad & 13,193 & 0.039 & 0.194 \\
\hline
\end{tabular}

Nota: Elaboración propia con base a ENDUTIH-2019.

La tabla 3 muestra una estadística descriptiva de los usuarios y no usuarios de banca electrónica. El análisis adicional muestra que las diferencias entre los rangos de edad son 
importantes: los usuarios menores de 28 años representan el 21\% del grupo de usuarios y el $40 \%$ del grupo de no usuarios. Ahora bien, entre los menores de 28 años, el 10\% son usuarios de banca electrónica; en el grupo de quienes están entre los 28 y 34 años de edad, el $24 \%$ son usuarios; entre los 34 y 44 años, el 23\%, y de los mayores de 44, solo el $18 \%$ son usuarios. En la tabla 3 también se muestran las pruebas de diferencias en medias de los usuarios y no usuarios, en todos los casos se muestran diferencias estadísticamente significativas.

Solo el 11\% de los usuarios de banca electrónica residen en la zona rural. De los hogares que usan banca electrónica, el 81 \% está conformado por 4 o menos integrantes.

En lo referente al tamaño de la población, cerca del 70 \% de los usuarios de banca electrónica se encuentran en ciudades de 100.000 y más habitantes. Cuanto más grande sea la ciudad en términos del número de habitantes, mayor es el uso de banca electrónica. En las ciudades de 100.000 y más habitantes, el 20.8 \% de los encuestados manifestó usar banca electrónica; en ciudades con menos de 2.500 habitantes, sólo el 7.1\%.

En lo que toca a los estratos socioeconómicos, se aprecia que cerca del $34 \%$ de las personas de estrato 4 reportaron usar banca electrónica, y solo el $5 \%$ de las personas de estrato 1 lo hacen. Por su parte, los jefes de hogar presentan mayores niveles de uso de banca electrónica. Se evidencian importantes diferencias en cuanto al género: el $20 \%$ las mujeres usan banca electrónica y solo el 14 \% los hombres. Entre los usuarios de banca electrónica, el 68 \% tienen por lo menos un grado de licenciatura; en el grupo de los no usuarios, solo el $20 \%$ tienen grado de licenciatura o superior.

Tabla 3. Descriptivas de los usuarios y no usuarios de banca electrónica

\begin{tabular}{|l|c|c|c|c|c|c|c|c|}
\hline \multicolumn{4}{|c}{ Usuarios } & \multicolumn{3}{c|}{ No usuarios } & \multicolumn{2}{c|}{$\begin{array}{c}\text { Diferencias de } \\
\text { media }\end{array}$} \\
\hline Variables & $\mathbf{N}$ & Mean & St. Dev. & N & Mean & St. Dev. & Diff & t \\
\hline Tamaño del hogar & 2,218 & 0.816 & 0.388 & 10,975 & 0.694 & 0.461 & -0.137 & -14.84 \\
\hline Rural & 2,218 & 0.115 & 0.320 & 10,975 & 0.282 & 0.450 & 0.166 & 20.92 \\
\hline $\begin{array}{l}\text { Tamaño de la } \\
\text { población }\end{array}$ & 2,218 & 1.630 & 1.054 & 10,975 & 2.214 & 1.302 & 0.585 & 23.14 \\
\hline Estrato & & & & & & & \\
\hline Edad & 2,218 & 3.049 & 0.966 & 10,975 & 2.295 & 1.010 & -0.758 & -33.77 \\
\hline Jefe & 2,218 & 2.692 & 1.142 & 10,975 & 2.381 & 1.276 & -0.449 & -16.70 \\
\hline Sexo & 2,218 & 0.523 & 0.500 & 10,975 & 0.370 & 0.483 & -0.190 & -16.59 \\
\hline Educación & 2,218 & 0.552 & 0.497 & 10,975 & 0.459 & 0.498 & -0.085 & -7.41 \\
\hline Alta freq internet & 2,218 & 0.684 & 0.465 & 10,975 & 0.202 & 0.402 & -0.502 & -47.93 \\
\hline Fraudes & 2,218 & 0.419 & 0.493 & 10,975 & 0.158 & 0.365 & -0.301 & -26.93 \\
\hline Ocupados & 2,218 & 0.091 & 0.288 & 10,975 & 0.036 & 0.186 & -0.058 & -9.25 \\
\hline Privacidad & 2,218 & 0.801 & 0.400 & 10,975 & 0.552 & 0.497 & -0.249 & -25.62 \\
\hline
\end{tabular}

Nota: Elaboración propia con base a ENDUTIH-2019.

Entre los encuestados que navegan en internet más de 6 horas, el $34 \%$ son usuarios de banca electrónica; de los que utilizan el internet entre 6 horas o menos, solo el $12 \%$ son usuarios de banca 
electrónica. En la tabla 3, se aprecia una gran diferencia en las horas de navegación entre los grupos de usuarios y no usuarios: más de 20 puntos porcentuales. De otra parte, el $80 \%$ de los que usan la banca electrónica reportan estar ocupados.

De las personas que fueron afectadas por fraudes o violación de su privacidad, en ambos casos, el 34 \% son usuarios de banca electrónica. También se observa que los usuarios más afectados por los problemas de privacidad y fraudes son quienes presentan mayor exposición en la red.

La tabla 4 relaciona las correlaciones entre las variables que se analizan en el presente estudio. En México, la educación a nivel de licenciatura o superior presenta la mayor correlación positiva con la adopción de banca electrónica. También muestran una correlación positiva las siguientes variables: el estrato socioeconómico, el hecho de navegar en la red más de seis horas, estar laborando, tener un hogar de 4 o menos integrantes, reportar fraude o violación de la privacidad y ser mujer.

Tabla 4. Matriz de correlaciones

\begin{tabular}{|c|c|c|c|c|c|c|c|c|c|c|c|c|c|}
\hline & 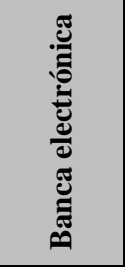 & 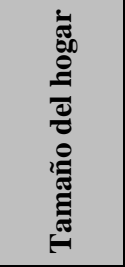 & 牙 & 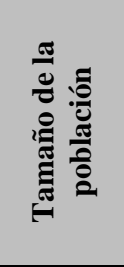 & 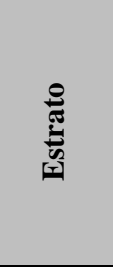 & $\sum_{\substack{\text { Ẽ } \\
\text { T }}}$ & 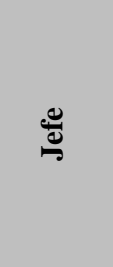 & ڤ્. & 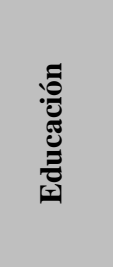 & 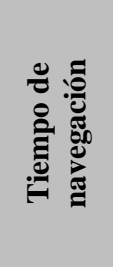 & 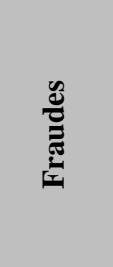 & 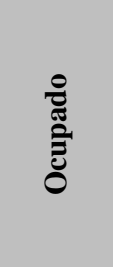 & 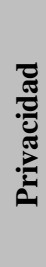 \\
\hline $\begin{array}{l}\text { Tamaño del } \\
\text { hogar }\end{array}$ & $0.10 * * *$ & 1 & & & & & & & & & & & \\
\hline Rural & $-0.14 * * *$ & $-0.07 * * *$ & 1 & & & & & & & & & & \\
\hline $\begin{array}{l}\text { Tamaño de } \\
\text { la población }\end{array}$ & $-0.17 * * *$ & $-0.11 * * *$ & $0.86^{* * *}$ & 1 & & & & & & & & & \\
\hline Estrato & $0.27 * * *$ & $0.16^{* * *}$ & $-0.46^{* * *}$ & $-0.58 * * *$ & 1 & & & & & & & & \\
\hline Edad & $0.09 * * *$ & $0.18^{* * *}$ & $-0.11 * * *$ & $-0.15 * * *$ & $0.19 * * *$ & 1 & & & & & & & \\
\hline $\begin{array}{l}\text { Banca } \\
\text { electrónica }\end{array}$ & 1 & $0.10 * * *$ & $-0.14 * * *$ & $-0.17 * * *$ & $0.27 * * *$ & $0.09 * * *$ & & & & & & & \\
\hline Jefe & $0.12 * * *$ & $0.23^{* * *}$ & $-0.07 * * *$ & $-0.08 * * *$ & $0.09 * * *$ & $0.42 * * *$ & 1 & & & & & & \\
\hline Sexo & $0.07 * * *$ & 0 & -0.02 & -0.01 & -0.01 & $-0.03 * * *$ & $0.31 * * *$ & 1 & & & & & \\
\hline Educación & $0.40 * * *$ & $0.13 * * *$ & $-0.20 * * *$ & $-0.23 * * *$ & $0.35^{* * *}$ & $0.10 * * *$ & $0.09 * * *$ & $0.03 * * *$ & 1 & & & & \\
\hline $\begin{array}{l}\text { Tiempo de } \\
\text { navegación }\end{array}$ & $0.24 * * *$ & $0.05^{* * *}$ & $-0.13 * * *$ & $-0.18 * * *$ & $0.21 * * *$ & $-0.14 * * *$ & -0.01 & $0.03 * *$ & $0.23 * * *$ & 1 & & & \\
\hline Fraudes & $0.10 * * *$ & 0 & $-0.05 * * *$ & $-0.06^{* * * *}$ & $0.06^{* * * *}$ & $0.02 *$ & $0.03 * * *$ & $0.04 * * *$ & $0.08 * * *$ & $0.07 * * *$ & 1 & & \\
\hline Ocupado & $0.19 * * *$ & $0.08 * * *$ & $-0.07 * * *$ & $-0.07 * * *$ & $0.04 * * *$ & $0.21 * * *$ & $0.31 * * *$ & $0.27 * * *$ & $0.14 * * *$ & $0.10^{* * *}$ & $0.05^{* * *}$ & 1 & \\
\hline Privacidad & $0.09 * * *$ & 0 & $-0.04 * * *$ & $-0.05 * * *$ & $0.07 * * *$ & $0.02 * *$ & $0.02 * *$ & $0.03 * * *$ & $0.07 * * *$ & $0.04 * * *$ & $0.29 * * *$ & $0.04 * * *$ & 1 \\
\hline
\end{tabular}

Por otro lado, residir en zona rural y vivir en poblaciones pequeñas, en términos del número de habitantes, muestran una correlación negativa en la adopción de banca electrónica en México. 


\section{Resultados y discusión}

En la tabla 5, se muestran los coeficientes del modelo de probabilidad lineal y los efectos marginales del modelo probabilístico. Dadas las bondades de la interpretación y luego de realizar las pruebas Akaike y Bayesianas, se elige el modelo de distribución logística.

Se observa que en hogares con 4 o menos integrante la probabilidad aumenta en 2.4 puntos porcentuales, respecto a familias con mayor número de integrantes. Este es el resultado esperado, y consistente con otras encuestas de hogares en México, por ejemplo, Orraca (2014) señala que hogares más grandes tienden a ser más pobres y enfrentan mayores restricciones económicas.

En la tabla 6 se analizan los efectos heterogéneos por el tamaño de la población, el efecto marginal es similar para las ciudades con menos de 100.000 habitantes; para las poblaciones de menor tamaño, no se encuentra significancia estadística determinante en la explicación del uso de banca electrónica en México. Por su parte, en la estadística descriptiva se aprecia poco uso de la banca electrónica por parte de los habitantes del área rural, pues no se evidencia un coeficiente estadísticamente significativo a la hora de adoptar la banca electrónica.

A medida que aumenta el estrato socioeconómico también lo hace la probabilidad de usar banca electrónica: pertenecer al estrato cuatro aumenta la probabilidad de acceder a la banca electrónica en 12 puntos porcentuales. Este incremento porcentual es de 15 puntos en las ciudades con más de 100.000 habitantes.

Como se puede apreciar en las tablas 5 y 6, ser mujer aumenta la probabilidad de adoptar banca electrónica en cerca de 3 puntos porcentuales, respecto a los hombres. El tamaño del efecto marginal se mantiene en las poblaciones grandes; en las pequeñas no existe significancia estadística.

Entre las variables de especial interés se encuentran los rangos de edad de la población. Se evidencia un incremento en la probabilidad de adoptar banca electrónica cuando aumenta el rango de edad. Entre los que se encuentran en el rango de 28 a 34 años, la probabilidad aumenta en cerca de 6 puntos porcentuales, respecto a los menores de 28 años.

Sin embargo, tal aumento es menor en el rango de los mayores de 44 años. Ahora bien, tales

incrementos porcentuales son mayores en las poblaciones grandes, pues es tres veces más probable que accedan a la banca electrónica las personas del rango de 28 a 34 años de poblaciones de más de 100.000 habitantes, respecto a los menores de 28 años de poblaciones de menos de 2.500 habitantes (0.08 vs 0.025$)$.

De otra parte, tener un grado de licenciatura o superior es la variable que incrementa en mayor proporción la adopción de banca electrónica: en 16 puntos porcentuales. Tal incremento es mayor en las poblaciones con más de 100.000 habitantes. De hecho, el incremento es el doble respecto a las poblaciones más pequeñas. Estos resultados son los esperados, pues se ve una buena aproximación al ingreso de los hogares. 
Tabla 5. Efectos marginales modelo logit y coeficientes lineales

\begin{tabular}{|c|c|c|}
\hline & (1) & (2) \\
\hline VARIABLES & MCO & Efectos marginales \\
\hline \multirow[t]{2}{*}{ Tamaño del hogar } & $0.0157^{* *}$ & $0.0214^{* * *}$ \\
\hline & $(0.00338)$ & $(0.00318)$ \\
\hline \multirow[t]{2}{*}{ Rural } & 0.00745 & -0.00114 \\
\hline & $(0.00776)$ & $(0.00829)$ \\
\hline \multirow[t]{2}{*}{ Estrato 2} & $0.0106^{*}$ & $0.0324^{* * *}$ \\
\hline & $(0.00411)$ & $(0.00630)$ \\
\hline \multirow[t]{2}{*}{ Estrato 3} & $0.0605^{* * *}$ & $0.0818^{* * *}$ \\
\hline & $(0.00680)$ & $(0.0101)$ \\
\hline \multirow[t]{2}{*}{ Estrato 4} & $0.128^{* * *}$ & $0.128^{* * *}$ \\
\hline & $(0.00900)$ & $(0.0114)$ \\
\hline \multirow[t]{2}{*}{ Sexo(Mujer =1) } & 0.0178 & $0.0232^{* * *}$ \\
\hline & $(0.00783)$ & $(0.00298)$ \\
\hline \multirow[t]{2}{*}{ Edad $>28-34$} & $0.0650^{*}$ & $0.0631^{* * *}$ \\
\hline & $(0.0238)$ & $(0.00583)$ \\
\hline \multirow{2}{*}{ Edad $>34-44$} & $0.0623^{* *}$ & $0.0606^{* * *}$ \\
\hline & $(0.0127)$ & $(0.0120)$ \\
\hline \multirow{2}{*}{ Edad $>44$} & $0.0260^{* *}$ & $0.0339^{* * *}$ \\
\hline & $(0.00770)$ & $(0.00898)$ \\
\hline \multirow{2}{*}{ Educación(>=Licenciatura) } & $0.240^{* * *}$ & $0.165^{* * *}$ \\
\hline & $(0.0195)$ & $(0.000805)$ \\
\hline \multirow{2}{*}{ Ocupado } & $0.0721^{* *}$ & $0.0796^{* * *}$ \\
\hline & $(0.0212)$ & $(0.00814)$ \\
\hline \multirow{2}{*}{ Usuario frecuente internet } & $0.120^{* * *}$ & $0.0911^{* * *}$ \\
\hline & $(0.00793)$ & $(0.0140)$ \\
\hline \multirow[t]{2}{*}{ Jefe } & 0.0159 & 0.0114 \\
\hline & $(0.00746)$ & $(0.00741)$ \\
\hline \multirow[t]{2}{*}{ Privacidad } & $0.0700^{* *}$ & $0.0450^{* * *}$ \\
\hline & $(0.0133)$ & $(0.0123)$ \\
\hline \multirow[t]{2}{*}{ Fraudes } & $0.0723^{* *}$ & $0.0469^{* * *}$ \\
\hline & $(0.0141)$ & $(0.0109)$ \\
\hline \multirow[t]{2}{*}{ Constante } & $-0.0791^{*}$ & \\
\hline & $(0.0266)$ & \\
\hline Observaciones & 13,193 & 13,193 \\
\hline Pseudo R2 (Mc Fadden's) & 0.226 & 0,2426 \\
\hline
\end{tabular}

Nota: Las estimaciones se realizaron con errores estándar robustos. Se realizaron las comparaciones entre los estimadores por Mínimos Cuadrados Ordinarios y Máxima Verosimilitud. En ambos casos las pruebas sugieren el modelo probabilístico, sumado a sus bondades en la estimación. La significancia de los coeficientes es, respectivamente, así: ${ }^{* *} \mathrm{p}<0.01,{ }^{* *} \mathrm{p}<0.05,{ }^{*} \mathrm{p}<0.1$. Se incluyeron clúster del tamaño de la población.

Estar ocupado aumenta la probabilidad de usar banca electrónica, en cerca de 8 puntos porcentuales, respecto a tener otra condición. Ese incremento porcentual va disminuyendo a medida que la ciudad es más pequeña. Es así como el incremento porcentual en la probabilidad de usar banca electrónica es cuatro veces mayor en las ciudades grandes, respecto a las más pequeñas. Por otro 
lado, navegar en Internet más de seis horas diarias presenta un importante porcentaje de crecimiento en la adopción de la banca electrónica en México como se observa en la tabla 6. El valor del efecto marginal es más alto para los habitantes de localidades que se encuentran entre 15.000 y 99.000 habitantes.

Tabla 6. Efectos marginales modelo logit. Heterogeneidad por tamaño de la población

\begin{tabular}{|c|c|c|c|c|}
\hline & $\begin{array}{c}100,000 \mathrm{y} \\
\text { más } \\
\text { habitantes }\end{array}$ & $\begin{array}{c}15,000 \text { a } \\
99,999 \\
\text { habitantes }\end{array}$ & $\begin{array}{c}2,500 \text { a } \\
14,999 \\
\text { habitantes }\end{array}$ & $\begin{array}{l}\text { menor a } \\
2500 \\
\text { habitantes }\end{array}$ \\
\hline \multirow[t]{2}{*}{ Tamaño del hogar } & $0.0223^{*}$ & $0.0388^{*}$ & 0.0183 & 0.00952 \\
\hline & $(0.0117)$ & $(0.0217)$ & $(0.0170)$ & $(0.00979)$ \\
\hline \multirow[t]{2}{*}{ Rural } & & & & -0.156 \\
\hline & & & & $(0.108)$ \\
\hline \multirow[t]{2}{*}{ Estrato 2} & $0.0350^{*}$ & 0.00378 & 0.0163 & $0.0252^{* * *}$ \\
\hline & $(0.0186)$ & $(0.0310)$ & $(0.0156)$ & $(0.00882)$ \\
\hline \multirow[t]{2}{*}{ Estrato 3} & $0.105^{* * *}$ & 0.0310 & $0.127^{* * *}$ & \\
\hline & $(0.0176)$ & $(0.0333)$ & $(0.0404)$ & \\
\hline \multirow[t]{2}{*}{ Estrato 4} & $0.158^{* * *}$ & 0.0570 & $0.176^{* * *}$ & -0.0426 \\
\hline & $(0.0180)$ & $(0.0401)$ & $(0.0359)$ & $(0.0347)$ \\
\hline \multirow[t]{2}{*}{ Sexo(Mujer =1) } & $0.0315^{* * *}$ & $0.0383^{* *}$ & 0.00245 & 0.0107 \\
\hline & $(0.00951)$ & $(0.0192)$ & $(0.0156)$ & $(0.00952)$ \\
\hline \multirow[t]{2}{*}{ Edad $>28-34$} & $0.0879 * * *$ & $0.0701^{* *}$ & 0.0322 & $0.0259 * *$ \\
\hline & $(0.0154)$ & $(0.0276)$ & $(0.0233)$ & $(0.0123)$ \\
\hline \multirow[t]{2}{*}{ Edad $>34-44$} & $0.0683^{* * *}$ & $0.107^{* * *}$ & -0.00270 & $0.0506^{* * *}$ \\
\hline & $(0.0139)$ & $(0.0277)$ & $(0.0211)$ & $(0.0131)$ \\
\hline \multirow[t]{2}{*}{ Edad $>44$} & $0.0372^{* * *}$ & $0.0613^{* *}$ & -0.00181 & $0.0379 * * *$ \\
\hline & $(0.0125)$ & $(0.0253)$ & $(0.0211)$ & $(0.0128)$ \\
\hline \multirow[t]{2}{*}{ Educación(>Licenciatura) } & $0.207^{* * *}$ & $0.162^{* * *}$ & $0.124^{* * *}$ & $0.0977^{* * *}$ \\
\hline & $(0.00819)$ & $(0.0172)$ & $(0.0144)$ & $(0.00884)$ \\
\hline \multirow[t]{2}{*}{ Ocupado } & $0.110^{* * *}$ & $0.0704^{* * *}$ & $0.0603^{* * *}$ & $0.0283^{* * *}$ \\
\hline & $(0.0106)$ & $(0.0218)$ & $(0.0172)$ & $(0.0101)$ \\
\hline \multirow[t]{2}{*}{ Usuario frecuente internet } & $0.0981^{* * *}$ & $0.128^{* * *}$ & $0.0597 * * *$ & $0.0818^{* * *}$ \\
\hline & $(0.00904)$ & $(0.0186)$ & $(0.0169)$ & $(0.00930)$ \\
\hline \multirow[t]{2}{*}{ Jefe } & 0.00515 & -0.00316 & $0.0323^{*}$ & $0.0220^{* *}$ \\
\hline & $(0.0103)$ & $(0.0213)$ & $(0.0174)$ & $(0.0106)$ \\
\hline \multirow[t]{2}{*}{ Privacidad } & $0.0452^{* *}$ & $0.112^{* * *}$ & 0.00941 & $0.0396^{*}$ \\
\hline & $(0.0190)$ & $(0.0383)$ & $(0.0421)$ & $(0.0210)$ \\
\hline \multirow[t]{2}{*}{ Fraudes } & $0.0536^{* * *}$ & 0.0141 & 0.0302 & $0.0626^{* * *}$ \\
\hline & $(0.0179)$ & $(0.0382)$ & $(0.0332)$ & $(0.0178)$ \\
\hline \multicolumn{5}{|l|}{ Constant } \\
\hline Observaciones & 6,800 & 1,435 & 1,586 & 3,372 \\
\hline Pseudo R2 (Mc Fadden's) & 0,2275 & 0,2073 & 0,2108 & 0,2139 \\
\hline
\end{tabular}

Nota: Las estimaciones se realizaron con errores estándar robustos. La significancia de los coeficientes es respectivamente: ${ }^{* * *} \mathrm{p}<0.01,{ }^{* *} \mathrm{p}<0.05,{ }^{*} \mathrm{p}<0.1$. 
Finalmente, en los resultados de la regresión logística descrita en la tabla 6, se observa que las personas que han reportado ser víctimas de fraude y haber tenido problemas que afectan su privacidad se encuentra asociado a un incremento en la probabilidad de usar banca electrónica. Esto significa que, a pesar de sus malas experiencias, deciden seguir utilizando los servicios.

La última estrategia empírica consiste en usar la metodología de randomforest, que Lizares (2017) define como una técnica de aprendizaje supervisado que genera múltiples árboles de decisión sobre un conjunto de datos de entrenamiento, de tal manera que los resultados obtenidos se combinan con el objetivo de obtener un único modelo más robusto, en comparación con los resultados de cada árbol por separado. Señalan Valverde \& Fernández (2019) que esta metodología indica y ordena las variables que determinan que un individuo utilice o no un servicio financiero digital. También resaltan la importancia del tipo de análisis, ya que a partir de los resultados se podrían conocer los factores principales que influyen en la toma de decisiones, frente a aquellos que simplemente inciden pues son de segundo orden o menos discriminantes.

En el presente estudio se dimensiona la adopción de la banca electrónica por parte de los individuos en México, a partir de las mismas variables utilizadas en los modelos de regresión. Se procedió a realizar la clasificación entre los no usuarios y los usuarios de banca electrónica, mediante el Algoritmo de randomforest, con el lenguaje de programación R. Se construyeron aleatoriamente 500 árboles de decisión con el conjunto de características establecidas en la tabla 1.

En el panel (a) de la figura 4, se pueden apreciar las variables que permiten encontrar mayor similitud entre los árboles; en el panel (b), se muestran las variables que reducen en mayor medida el error de estimación. Se encuentra que las principales variables son, en su orden:

- La educación: en la medida en que los individuos tengan mayores niveles educativos (licenciatura y niveles superiores), con mayor probabilidad serán usuarios de banca electrónica en México. Este es un resultado esperado, dado que es un buen proxy del ingreso de los individuos.

- Ser usuario frecuente de Internet: a medida que un individuo se encuentre por encima del promedio mundial diario de navegación en Internet, se irá convirtiendo en usuario de banca electrónica más fácilmente.

- Ocupación: estar trabajando, factor que también se relaciona con los ingresos disponibles.

- Estrato socioeconómico: cuanto más elevado sea el estrato, habrá mayor conocimiento y adopción de la banca electrónica, respecto a los estratos menos favorecidos. 

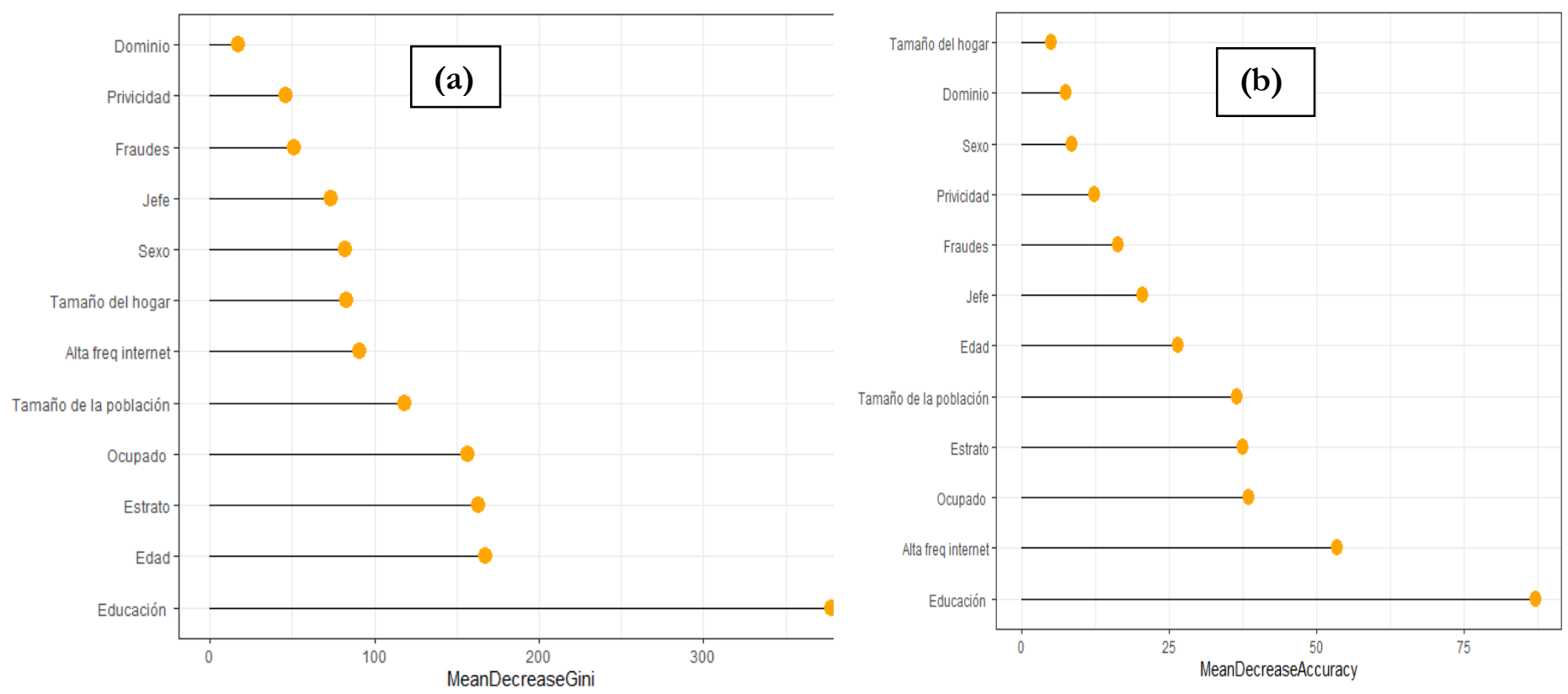

Figura 3. Predicción de los árboles de decisión de las variables más importantes para la predicción de la adopción de banca electrónica

Nota: (a)Relaciona la similitud entre los árboles comparados y (b) las variables que reducen en mayor medida la estimación. Las medidas de sensibilidad y ajuste se pueden aprecia en el anexo 1.

Con base en los principales factores que se muestran en la figura 3, se puede predecir en casi un 90 \% si un individuo adoptará o no la banca electrónica en México. En la figura 4, se muestra la secuencia en la ocurrencia de factores determinantes que afectan a los individuos que no adoptan la banca electrónica. La secuencia empieza por la condición de tener niveles educativos menores a la licenciatura; sigue con el tiempo de navegación en Internet menor de seis horas diarias; luego, aparecen los hechos de vivir en el estrato socioeconómico uno o dos, no ser jefe de hogar y estar desempleado.

En el extremo derecho se clasifican los individuos que sí adoptan la banca electrónica. Los factores determinantes son, en su orden: tener licenciatura o mayores niveles educativos, estar empleados, vivir en estrato 3 y 4, y navegar más de seis horas diarias en la red. Estos resultados están en sintonía con resultados de los efectos marginales de la regresión logística, pero ofrecen la ventaja de establecer un orden secuencial que permite enfocar mejor las políticas orientadas a aumentar la inclusión financiera. 


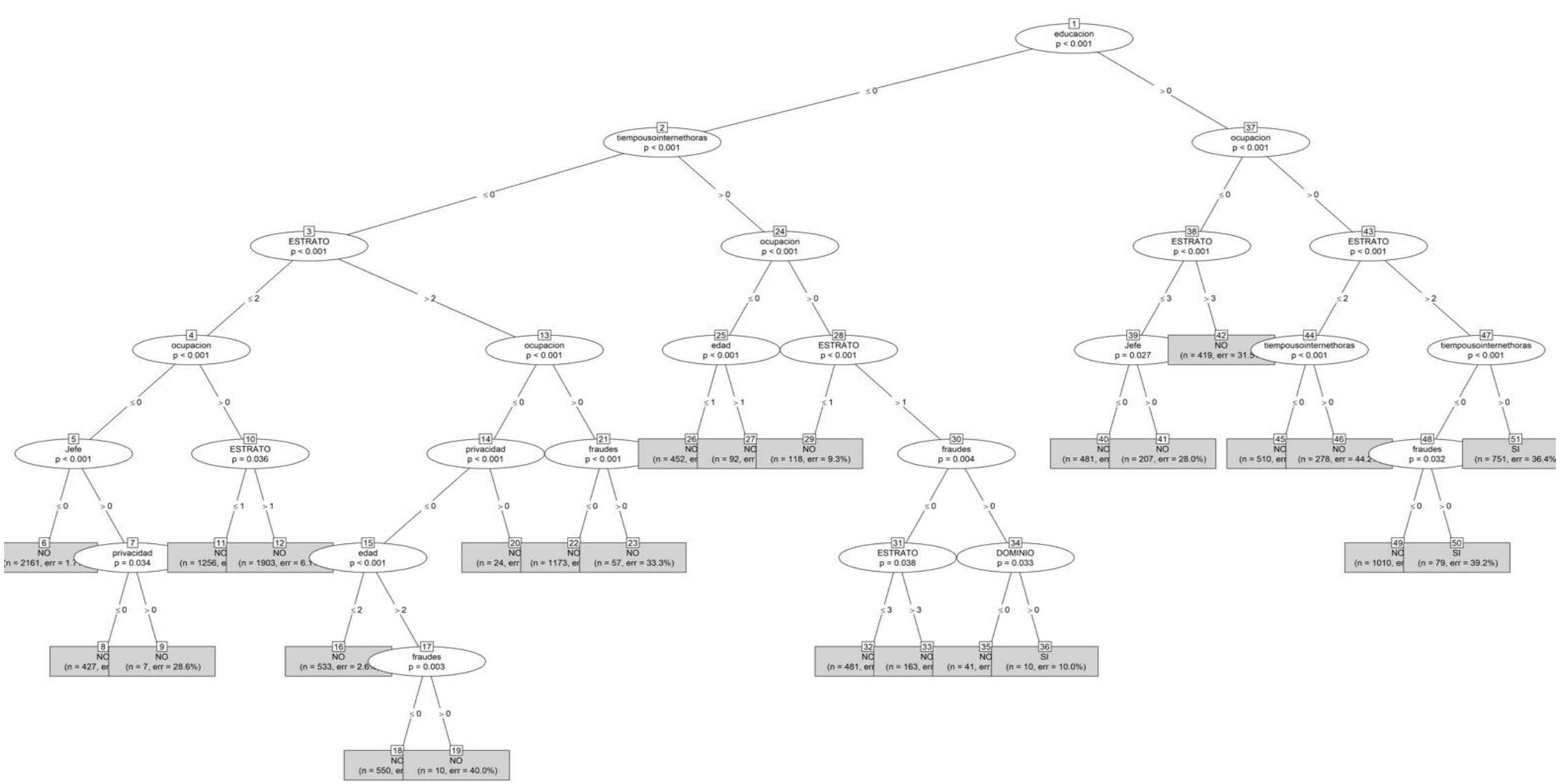

Figura 4. Árbol de decisión sobre la adopción de la banca electrónica en Méxic

Nota: Elaborada en el lenguaje de programación R con el paquete RandomForest, que permite realizar los entrenamientos necesarios para clasificar según las variables a los individuos que adoptan o no la banca electrónica en México. 
En coherencia con lo planteado por Yates (2020), Lee \& Lee (2000), Mejía \& Quintero (2016) y Angelakopoulos \& Mihiotis (2011), los resultados del modelo probabilístico y el árbol de decisión muestran con claridad que poseer mayor nivel educativo tiene una incidencia positiva en la probabilidad de adopción de la banca electrónica. Y en coherencia con lo planteado por Inegbedion (2018), Mejía \& Quintero (2016) y Szopiński (2016), los resultados muestran que las personas que navegan más horas al día en Internet tienen mayor probabilidad de usar la banca electrónica.

Esta misma probabilidad positiva se evidencia en la población con edades entre los 28 y 39 años, las personas ocupadas y las categorizadas en estratos 4 y 5 . Estos resultados son insumos para que se puedan orientar políticas públicas sectorizadas que generen un mayor nivel de eficacia a la hora de corregir la exclusión financiera de la población.

Antes de cerrar, queremos recordar que en México las personas que reportan haber sido víctimas de fraudes o haber tenido algún problema con su privacidad tienen mayor probabilidad de adoptar banca electrónica. Lo cual resulta contrario a lo establecido por Vejačka \& Stofa (2017) en Eslovaquia; Kapinus \& Skrygun (2014) en Ucrania; Karimzadeh \& Alam (2012) en la India; Inegbedion (2018) en Nigeria, y Jerene \& Sharma (2020) en Etiopia, donde la percepción de inseguridad disminuye la probabilidad de adoptar la banca electrónica.

Los resultados muestran que a las personas de estrato social más alto y más educadas se les facilita el acceso a la banca electrónica. Lo que sugiere la necesidad de una propuesta más inclusiva para otros segmentos de la población. En este sentido, Mungaray, Gonzalez \& Osorio (2021) señalan que aumentar los niveles de educación financiera puede mejorar a su vez los niveles de inclusión social y bienestar, sin importar el estrato social del individuo.

\section{Conclusiones, recomendaciones finales}

Este artículo presenta un estudio empírico sobre la adopción de la banca electrónica en México. Mediante información a nivel de individuo, métodos tradicionales de econometría y técnicas de aprendizaje supervisado de Machine Learning, se analizaron los determinantes de la adopción de la banca electrónica. Las dos técnicas usadas se complementan: mientras la primera estableció los cambios en la probabilidad de adoptar la banca electrónica, la segunda estableció una secuencia ordenada de las variables empleadas en el modelo, según su incidencia en la adopción de la banca electrónica. Se encontró que los individuos con mayores niveles educativos, asiduos a la navegación en la red y pertenecientes a los estratos más altos, son quienes ostentan las variables más relevantes tanto en magnitud como en orden para adoptar la banca electrónica.

Los retos que ha generado la propagación del COVID-19 demandan cambios de comportamiento y adopción de diversas acciones que disminuyan los riesgos asociados a la pandemia. La banca electrónica juega un rol fundamental para facilitar la vida de las personas, en lo referente al manejo de sus recursos financieros. Por lo tanto, establecer y analizar las principales determinantes, así como la secuencia en que ellas influyen sobre la toma de decisiones de los individuos se convierte en un elemento relevante para proponer políticas públicas de inclusión financiera. Políticas diseñadas no solo para las personas más educadas y con mejores condiciones financieras sino para todos los segmentos de la población. 
En lo referente a las políticas públicas, es posible generar un aumento en la inclusión financiera mediante la adopción de productos digitales, se podría focalizar en programas de educación financiera informal y formal principalmente en los estratos socioeconómicos uno y dos. También, la disminución de brechas digitales mediante la alfabetización digital entre la población de mayor edad. Así mismo, programas para los informales que representa una porción importante de la población ocupada en México, con el fin de que conozcan los medios digitales para realizar las operaciones bancarias. Lo anterior demanda acciones para todos los actores involucrados en el ecosistema financiero y las instituciones de formación de capital humano.

En México, el porcentaje de uso de banca electrónica entre los encuestados es solo del 16.8\%. Lo que se puede considerar una oportunidad para que los hacedores de políticas públicas y el sector privado puedan, de manera estratégica, explotar la posibilidad de ampliar la inclusión financiera y la penetración de los servicios financieros a través de la banca electrónica. Así, podrían mitigar el aumento de los contagios de COVID -19 generados por las aglomeraciones y el contacto físico entre las personas.

\section{Referencias}

[1] Ali, M., Khalid, S., \& Omer, E. A. (2020). The Influence of the Information and Communication Technologies Regulation Policies in Sudan on Electronic Banking Usage. 693-700. doi:10.1007/978-3030-36671-1_63

[2] Álvarez, R. A. R., Calvo, J. A. P., Torrado, C. A. M., \& Mondragón, J. A. U. (2013). Fundamentos de econometría intermedia: teoría y aplicaciones. Universidad de los Andes.

[3] Angel, G.A. D. (2016). Limits to Cashless Payments and the Persistence of Cash. Hypotheses About Mexico. In: Batiz-Lazo B., Efthymiou L. (eds) The Book of Payments. Palgrave Macmillan, London. Doi:10.1057/978-1-137-60231-2_12

[4] Angelakopoulos, G., \& Mihiotis, A. (2011). E-banking: Challenges and oportunities in the Greek banking sector. Electronic Commerce Research, 11, 297-319. doi:10.1007/s10660-011-9076-2

[5] Araiza, V. d., \& Pedraza, S. Y. (2019). Aceptación de servicios financieros en línea por los consumidores del área metropolitana de Monterrey. Apuntes Contables, 11-38. Doi:10.18601/16577175.n24.02. Obtenido de https://core.ac.uk/download/pdf/230105423.pdf

[6] Avendaño, C. (2017). Los retos de la banca digital en México. IUS. Revista del Instituto de Ciencias Jurídicas de Puebla A.C, 12(41), 87-108. Obtenido de https://www.redalyc.org/pdf/2932/293258387006.pdf

[7] Banco Interamericano de Desarrollo. (2018). FINTECH América Latina 2018 Crecimiento y consolidación. BID Finnovista, 1-137. Obtenido de https://publications.iadb.org/es/fintech-americalatina-2018-crecimiento-y-consolidacion

[8] Bimha, A. (2015). Complaints of Electronic Banking juxtaposed with Financial Inclusion - A South African Perspective. Banks and Bank Systems, 13-25.

[9] Borraz, M. J., Bordonaba, J. V., \& Polo, R. (2017). FUNCTIONAL BARRIERS TO THE ADOPTION OF ELECTRONIC BANKING: THE. Revista de Economía Aplicada, XXV(75), 87-107. Obtenido de https://www.redalyc.org/pdf/969/96954075004.pdf

[10] Flavián, C., Guinaliu, M., \& Torres, E. (2006). How bricks-and-mortar attributes affect online banking adoption. Revista Internacional de, 24(6), 406-426. Doi:10.1108/02652320610701735 
[11] Fondo Monetario Internacional. (2019). Fintech in Latin America and the Caribbean: Stocktaking. 2-52. Obtenido de https://www.imf.org/en/Publications/WP/Issues/2019/03/26/Fintech-in-Latin-America-and-theCaribbean-Stocktaking-46677

[12] Global FinTech Adoption Index. (2019). As FinTech becomes the norm, you need to stand out. 1-42. Doi:10.47473/2020rmm0059. Obtenido de https://assets.ey.com/content/dam/ey-sites/eycom/en_gl/topics/banking-and-capital-markets/ey-global-fintech-adoption-index.pdf

[13] Ikhsanova, L., \& Protsko, E. (2016). Electronic banking: Tool of transforming the interaction between banks and clients and improving the service quality of the Russian banks. JOUR, 73-79.

[14] Inegbedion, H. (2018). Factors that Influence Customers' Attitude toward Electronic Banking in Nigeria. Journal of Internet Commerce. doi:10.1080/15332861.2018.1463482

[15] INEGI. (2019). Encuesta Nacional sobre Disponibilidad y Uso de Tecnologías de la Información en los Hogares (ENDUTIH) 2019.

[16] Jerene, W., \& Sharma, D. (2020). The Adoption of Banking Technology and Electronic Financial Services: Evidence from Selected Bank Customers in Ethiopia. International Journal of Electronic Finance, 3103028. doi:10.1504/IJEF.2019.104080

[17] Kapinus, L., \& Skrygun, N. (2014). Development of Electronic Banking Technologies in Ukraine. Economics and management of enterprises, 55-58.

[18] Karimzadeh, M., \& Alam, D. (2012). Electronic banking challenges in India: An empirical investigation. Interdisciplinary journal of contemporary research in business, IV (2), 31-45.

[19] Lassala, N. C., Ruiz, C., \& Blas, S. (2007). Los servicios financieros en Internet: un estudio de las decisiones de compra. Boletín económico de ICE, Información Comercial Española, 2906, 19-36. doi: ISSN 02148307

[20] Lavalleja, M. (2020). Panorama de las fintech: principales desafíos y oportunidades para el Uruguay. serie Estudios y Perspectivas-Oficina de la CEPALen Montevideo(48), 1-36.

[21] Lee, E.-J., \& Lee, J. (2000). Haven't Adopted Electronic Financial Services Yet? The Acceptance and Diffusion of Electronic Banking Technologies. Financial Counseling and Planning, XI (1), 49-60.

[22] Lizares, M. (2017). Universidad Nacional Mayor de San Marcos. Doi:10.33539/avpsicol.2020.v28n2.2250. Recuperado el 10 de marzo de 2020 de http://cybertesis.unmsm.edu.pe/bitstream/handle/cybertesis/7122/Lizares_cm. pdf?sequence $=1 \&$ isAllowed $=\mathrm{y}$

[23] Mejía, B. A., \& Quintero, W. (2016). Determinantes del uso de la banca electrónica en Colombia. Finnova, II (3), 15 - 27.

[24] Meyer, T. (2006). Banking online boosts and curbs customer loyalty. Deutsche bank research, 5.

[25] Mobayen, N., Ghahremani, A., Hasanpoor, M., \& Joorbonyan, S. (2015). Investigating the impact of the level of using electronic banking on gaining competitive advantage: (Case Study: Melli bank branches in Mazandaran province). I J A B E R, XIII(6), 4175-4192. Obtenido de https://serialsjournals.com/abstract/69295_4175-4192.pdf

[26] Mohammadi S, A. S. (2008). ECC-Based Biometric Signature: A New Approach in Electronic Banking Security. ISECS. Doi:10.1109/isecs.2008.98

[27] Muwando, S., \& Webb, M. (2014). Managers and Employees' Perception of the Impact of Electronic Banking on Bank Operational Efficiency. A Case of Commercial Banks in Zimbabwe. Mediterranean Journal of Social Sciences, V (23), 85-90. Doi:10.5901/mjss.2014.v5n23p85. Obtenido de https://pdfs.semanticscholar.org/2d37/d8639c2edf3ac194637147bef3db2dfe76ae.pdf?_ga=2.1145 66599.1363195991.1598107975-1290868695.1598107975 
[28] Mungaray, A. ., Gonzalez Arzabal, N. ., \& Osorio Novela, G. .. (2021). Educación financiera y su efecto en el ingreso, en México. Problemas Del Desarrollo. Revista Latinoamericana De Economía, 52(205). https://doi.org/10.22201/iiec.20078951e.2021.205.69709

[29] Orraca, P. (2014). El trabajo infantil en México y sus causas. Problemas del desarrollo, 45(178), 113137.https://doi.org/10.1016/s0301-7036(14)70878-8

[30] Ramírez, B. C., García, R. ,., \& Aranibar, G. ,. (2019). La relación de la confianza, la actitud y el compromiso en el uso de la banca en línea. Revista de Investigación Latinoamericana en Competitividad Organizacional. Obtenido de https://www.eumed.net/rev/rilco/03/banca-linea.html

[31] Secretaría de Salud México. (2021). Datos Abiertos. Dirección General de Epidemiología. Todo sobre el COVID-19. México. Obtenido de https://datos.covid-19.conacyt.mx/\#COMNac

[32] Suárez, S. L. (2016). Poor people's money: The politics of mobile money in Mexico and Kenya. Telecommunications Policy, 40(10-11), 945-955. https://doi.org/10.1016/j.telpol.2016.03.001

[33] Szopiński, T. S. (2016). Factors affecting the adoption of online banking in Poland. Journal of Business Research, 4761-4768. doi: 10.1016/j.jbusres.2016.04.027.

[34] Valverde, S. C., \& Fernández, F. R. (2019). Patrones de acceso a la banca digital: aproximaciones tradicionales, aprendizaje automático y neuroeconomía. Papeles de Economía Española, (162), 14-177.

[35] Vejačka, M. (2014). Customer acceptance of electronic banking: Evidence from Slovakia. Journal of Applied Economic Sciences, IX, 514-522. Obtenido de https://www.researchgate.net/publication/277980429_Customer_acceptance_of_electronic_banking _Evidence_from_Slovakia/citation/download

[36] Vejačka, M., \& Stofa, T. (2017). Influence of security and trust on electronic banking adoption in Slovakia. E+M Ekonomie a Management, XX, 135-150. doi:10.15240/tul/001/2017-4-010

[37] Wanjiku, K., \& Mbugua, D. (2018). Effect of Electronic Banking on Performance of Commercial Banks in Kenya. International Journal of Social Sciences and Information Technology, IV (5), 393-407.

[38] Yates, S. (2020). Factors Associated with Electronic Banking Adoption. Journal of Financial Counseling and Planning, 31, JFCP18. doi:10.1891/JFCP-18-00079

\section{NOTAS}

1. Adicionalmente, uno de los principales atractivos de los árboles de decisión es que pueden aceptar un problema no lineal extremadamente complejo, con una amplia gama de posibilidades variables predictoras, y reducirlo a un procedimiento que sea fácilmente entendido por un usuario no técnico.

2. La variable estrato resulta de un componente principal que realiza INEGI tiene más de 20 variables, no solo del ingreso, lo que los convierte en un índice de los activos.

3. 3Se definió una variable dummy que toma el valor de uno, si los usuarios usan más de 6 horas diarias internet. Ese valor es el promedio mundial de navegación según Hootsute, en su informe digital de 2019. Para el caso de México, el promedio es 8 horas al día. 


\section{ANEXOS}

\section{A1. Matriz de confusión y medidas de sensibilidad}

Reference

Prediction NO SI

NO 7483778

SI 223779

Accuracy : 0.8919

$95 \%$ CI : $(0.8854,0.8982)$

No Information Rate : 0.8319

P-Value $[$ Acc $>$ NIR] : $<2.2 \mathrm{e}-16$

Kappa : 0.5495

Mcnemar's Test P-Value : $<2.2 \mathrm{e}-16$

\begin{tabular}{|c|c|}
\hline Sensitivity $: 0.9711$ & Specificity : 0.5003 \\
\hline Pos Pred Value $: 0.9058$ & Neg Pred Value $: 0.7774$ \\
\hline Prevalence $: 0.8319$ & Detection Rate $: 0.8078$ \\
\hline Detection Prevalence $: 0.8918$ & Balanced Accuracy $: 0.7357$ \\
\hline
\end{tabular}

'Positive' Class : NO

\section{A2. Variación del error}

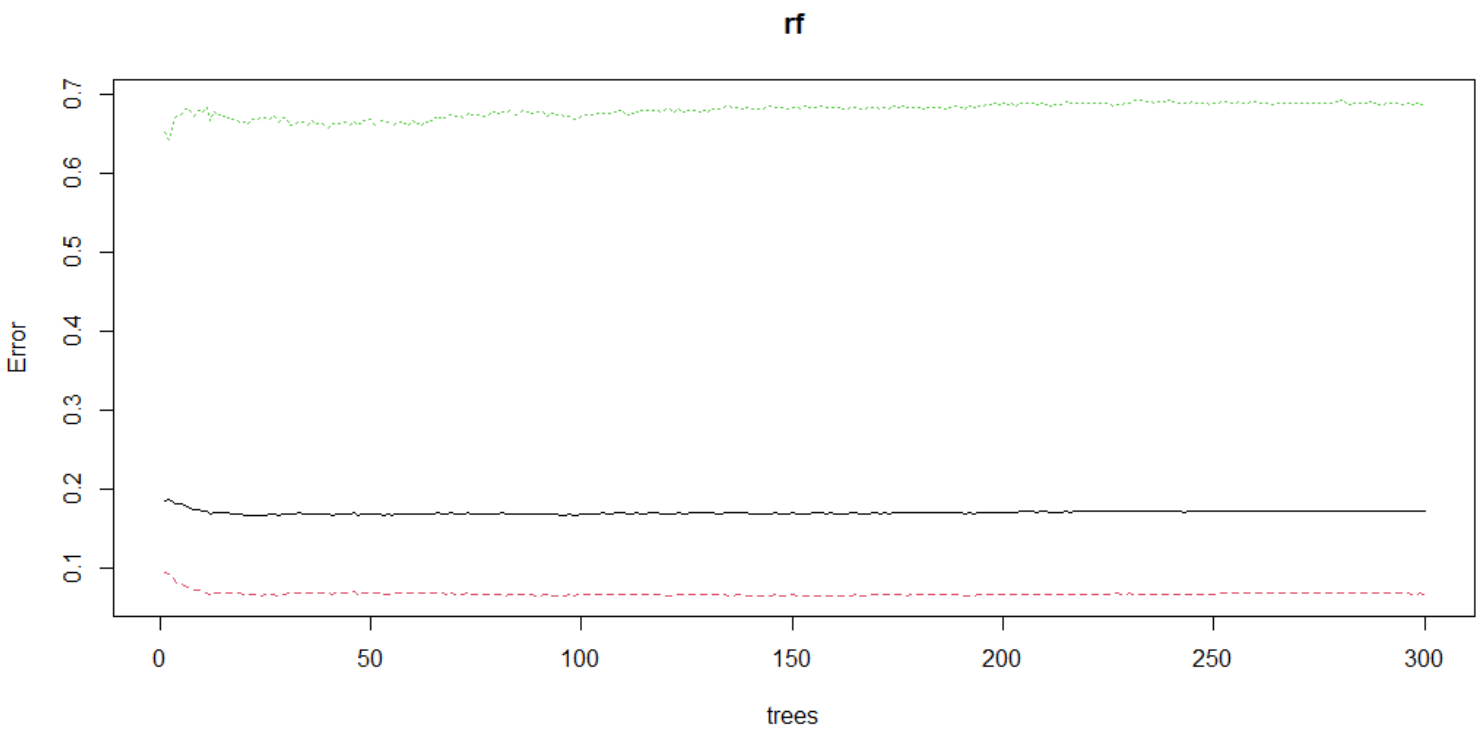




\section{A3. Histograma de los árboles}

\section{No. of Nodes for the Trees}

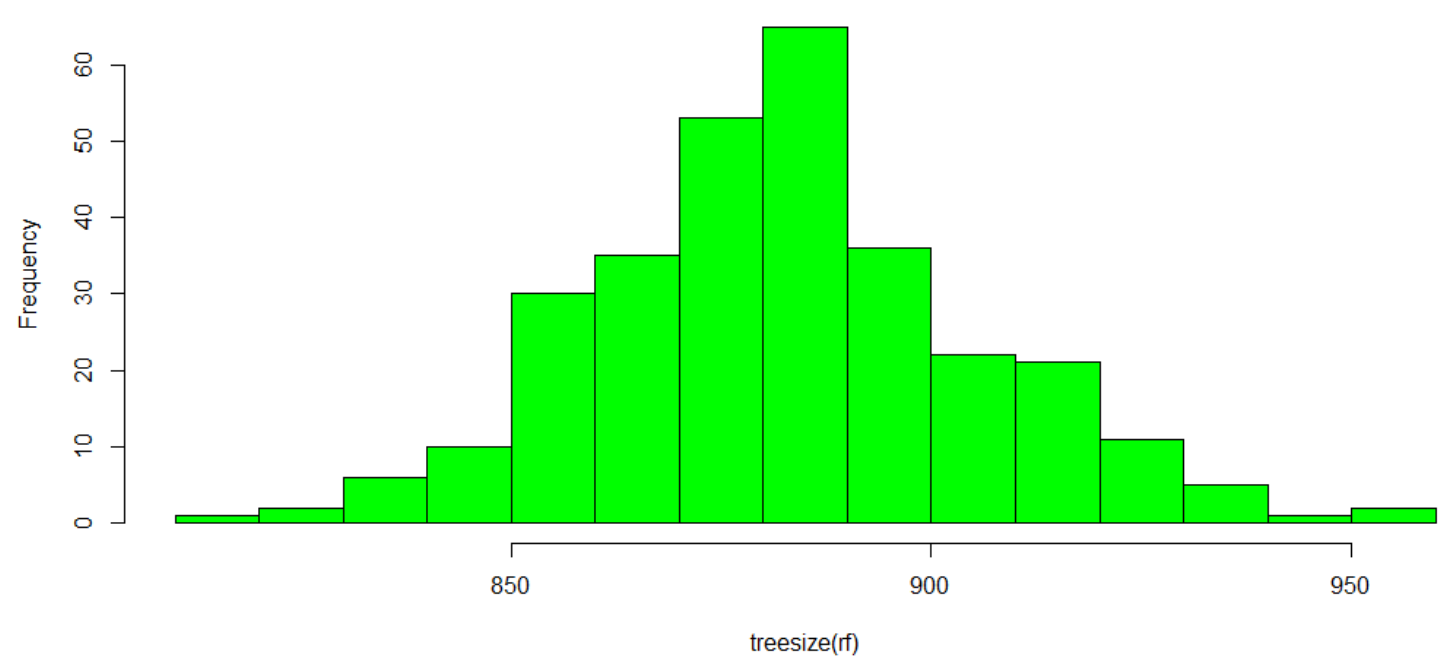

